\title{
Application of the geometric morphometrics approach in the discrimination of morphological traits between brown trout lineages in the Danube Basin of Croatia
}

\author{
Ivan Špelić ${ }^{1}$, Andrea Rezić ${ }^{1, *}$, Tamara Kanjuh ${ }^{2}$, Ana Marić ${ }^{2}$ Ivana Maguire ${ }^{4}$, Predrag Simonović ${ }^{2,3}$, \\ Tena Radočaj ${ }^{1}$ and Marina Piria ${ }^{1}$ \\ ${ }^{1}$ University of Zagreb Faculty of Agriculture, Svetošimunska cesta 25, 10000 Zagreb, Croatia \\ ${ }^{2}$ Faculty of Biology, University of Belgrade, Studentski trg 16, 11000 Belgrade, Serbia \\ ${ }^{3}$ Institute for Biological Research Siniša Stanković - National Institute of Republic of Serbia, University of Belgrade, Bulevar despota \\ Stefana 142, 11060 Belgrade, Serbia \\ ${ }^{4}$ University of Zagreb, Faculty of Science, Department of Biology, Rooseveltov trg 6, 10000 Zagreb, Croatia
}

Received: 5 March 2021 / Accepted: 30 April 2021

\begin{abstract}
Brown trout is a salmonid fish with a natural range extending throughout western Eurasia and North Africa. Due to its commercial value, it has also been introduced worldwide. In continental Croatia, introduced trout of the Atlantic lineage hybridizes with native trout of the Danubian lineage, threatening the native genetic diversity. The geometric morphometrics approach was used in this study to analyse changes in shape between native trout, introduced trout and their hybrids, classified a priori by molecular phylogenetic analyses. A total of 19 landmarks and semi-landmarks were used to capture the shape of 92 trout individuals belonging to two lineages and their hybrids. Canonical variate analysis and discriminant function analysis were used to analyse and describe shape variation. A significant difference was found between the shape of the Atlantic lineage trout and both Danubian lineage trout and hybrids, with the most prominent differences in body depth, head length and eye size. No statistically significant shape differences were observed between Danubian lineage trout and the hybrids. The observed significant differences in shape could be the result of genetic diversity or trout phenotypic plasticity. Further studies are needed to clarify the origin of this variation in shape.
\end{abstract}

Keywords: Salmonid fish / introduction / shape analysis / black sea basin / hybridization

\begin{abstract}
Résumé - Application de l'approche morphométriques géométrique dans la discrimination des traits morphologiques entre les lignées de truites brunes dans le bassin du Danube en Croatie. La truite brune est un poisson salmonidé dont l'aire de répartition naturelle s'étend à toute l'Eurasie occidentale et à l'Afrique du Nord. En raison de sa valeur commerciale, elle a également été introduite dans le monde entier. En Croatie continentale, la truite introduite de la lignée atlantique s'hybride avec la truite indigène de la lignée danubienne, menaçant la diversité génétique indigène. L'approche morphométrique géométrique a été utilisée dans cette étude pour analyser les changements de forme entre les truites indigènes, les truites introduites et leurs hybrides, classées a priori par des analyses phylogénétiques moléculaires. Un total de 19 points de repère et semi-points de repère ont été utilisés pour saisir la forme de 92 individus de truites appartenant à deux lignées et à leurs hybrides. L'analyse canonique des variables et l'analyse de la fonction discriminante ont été utilisées pour analyser et décrire la variation de forme. Une différence significative a été trouvée entre la forme de la truite de la lignée atlantique et celle de la truite de la lignée danubienne et de ses hybrides, les différences les plus importantes concernant la profondeur du corps, la longueur de la tête et la taille des yeux. Aucune différence de forme statistiquement significative n'a été observée entre les truites de la lignée danubienne et les hybrides. Les différences significatives de forme observées pourraient être le résultat de la diversité génétique ou de la plasticité phénotypique des truites. Des études supplémentaires sont nécessaires pour clarifier l'origine de cette variation de forme.
\end{abstract}

Mots clés : Poissons salmonidés / introduction / analyse de forme / bassin de la mer Noire / hybridation

\footnotetext{
*Corresponding author: arezic@agr.hr
} 


\section{Introduction}

Brown trout (Salmo trutta) is one of the best studied and most widely distributed fish species, with a natural range from Europe and Asia to North Africa, and introductions recorded worldwide (Bernatchez, 2001; Kalayci et al., 2018). This wide distribution is primarily related to human interests, given its commercially importance in both aquaculture and angling (Saint-Pé et al., 2019). Eurasian brown trout exhibit high phenotypic diversity linked to their complex evolutionary history (Bernatchez, 2001; Leitwein et al., 2017), and are thus often referred to as the brown trout complex (Delling et al., 2020). This diverse evolutionary history results from the ability of brown trout to use the sea and coastal zone to migrate long distances in the past, successfully invading suitable habitats (Berrebi, 2015). Generally, nine main phylogeographic lineages of brown trout complex are recognized with various geographical extents: four are subcontinental lineages (Atlantic, Mediterranean, Danubian and Adriatic), three are regional lineages (Marmoratus in the northern Adriatic Sea, North African in Morocco, Algeria and Sicily, and Duero in the northwestern Iberian basins) and two are local lineages limited to specific geographical areas (Tigris in Turkey, and Dades in Morocco) (Snoj et al., 2011; Sanz, 2018).

In the Balkan Peninsula, the taxonomic status of the brown trout complex has not yet been resolved due to the high variety of phenotypes present (Georgijev, 2003). The origin of such diversity could be in the many deliberate historical introductions, reintroductions and translocations of this species from different areas over the past 150 years, due to food shortages, depletion of fish stocks, sport fishing, and profit, while other introductions have been accidental (Pofuk et al., 2017). In Croatia, the Danubian lineage of brown trout (tentative Salmo labrax) is considered native to the Danube Basin, while the Adriatic lineage (tentative Salmo farioides) is native to the Adriatic Basin (Škraba Jurlina et al., 2020). Historically, the Atlantic lineage of brown trout was introduced into suitable habitats throughout the region as stocking material from fish farms, and this activity appears to be ongoing (Piria et al., 2020; Ivić et al., 2021). Cross-breeding between introduced Atlantic and native lineages has recently been detected in the region through molecular analyses, forming hybrid populations that pose a threat to native genetic diversity (Kanjuh et al., 2020; Škraba Jurlina et al., 2020; Ivić et al., 2021). This interspecific hybridization caused by natural or anthropogenic events is a common phenomenon in freshwater fishes (Scribner et al., 2001), and has been described in spined loaches (Vasil'eva and Vasil'ev, 2019), barbels (Khaefi et al., 2018) and bitterling (Uemura et al., 2018). Rates of hybridization are increasing dramatically worldwide, and could lead to the direct or indirect extinction of many endangered species (Allendorf et al., 2001). Hybrid salmonids are generally difficult to distinguish from parental taxa using morphological features (Jansson et al., 1991; Matthews et al., 2000; Kalayci et al., 2018), making population control difficult.

Several studies have employed classical morphometric and meristic traits to analyse and discriminate populations between and within brown trout lineages (Simonović et al., 2007; Hermida et al., 2009; Liasko et al., 2012; Lorenzoni et al., 2019; Delling et al., 2020; Piria et al., 2020). Less attention has been given to the analysis of body size and shape variation using the geometric morphometrics (GM) approach, even though the GM method has proven suitable for confirming the discrimination of alien and native lineages previously differentiated by molecular analyses (Monet et al., 2006; Fruciano et al., 2014). According to Webster and Sheets (2010), two general styles of GM are recognized: landmarkbased and outline-based, each of which has advantages depending on the characteristics of the sample. Landmarkbased GM is currently the most commonly used thanks to the short sample preparation time required, and the smaller number of landmarks and semi-landmarks needed for qualitative analyses. On the other hand, the outline-based technique requires more time for sample preparation and it is mostly applied in entomology (Chaiphongpachara, 2018). The GM based on landmarks captures the shape of organisms and can indicate subtle morphological differences between specimens or even populations of interest (Zelditch et al., 2004; Valentin et al., 2008; Fruciano et al., 2014, 2020).

To date, the GM approach has only been applied to native Mediterranean trout populations in contact with the introduced Atlantic lineage in France and Italy (Monet et al., 2006; Fruciano et al., 2014) and has not yet been performed on any of the brown trout populations of the Balkan Peninsula. The main hypothesis of this study was that the body shape of the nonintrogressed native haplogroup of brown trout differs from the body shape of the alien haplogroup and their hybrids. Therefore, the aim was to analyse variation in body shape between native Danubian and introduced Atlantic lineages of brown trout and their hybrids in streams of the Danube Basin in continental Croatia using the GM method.

\section{Materials and methods}

\subsection{Study area, sampling and preparation for morphometric analyses}

Brown trout were collected by electrofishing (Hans Grassl $2.2 \mathrm{~kW}$ ) from 10 streams in continental Croatia, in three mountain areas: Gorski Kotar (Bresni potok, Mala Lešnica, Curak), Mt. Žumberak (Kupčina, Slapnica) and Mt. Papuk (Jankovac, Brzaja, Veličanka, Toplica and Orljava) (Fig. 1). All sampling was conducted in daytime during May in two years, 2017 and 2018. Electrofishing permits were issued by the Ministry of Agriculture and Ministry of Environmental Protection and Energy. Additionally, 10 specimens belonging to the Atlantic lineage were purchased at the Vrabac fish farm in continental Croatia (Fig. 1, Tab. 1). In total, 92 fish over $100 \mathrm{~mm}$ total length were sacrificed, frozen and stored. Sex was determined by gonad observation. After thawing, fish were photographed for geometric morphometric analyses. Photographs were taken by a digital camera mounted on a camera stand, at a sufficient distance from the fish $(650 \mathrm{~mm})$ to reduce the parallax effect (Fruciano, 2016). Prior to GM analyses, molecular phylogenetic analysis using control region mitochondrial DNA was conducted on the same samples (see Kanjuh et al., 2020 for details), which revealed the presence of two phylogenetic lineages, Danubian and Atlantic, while restriction analysis of the lactate dehydrogenase gene locus 


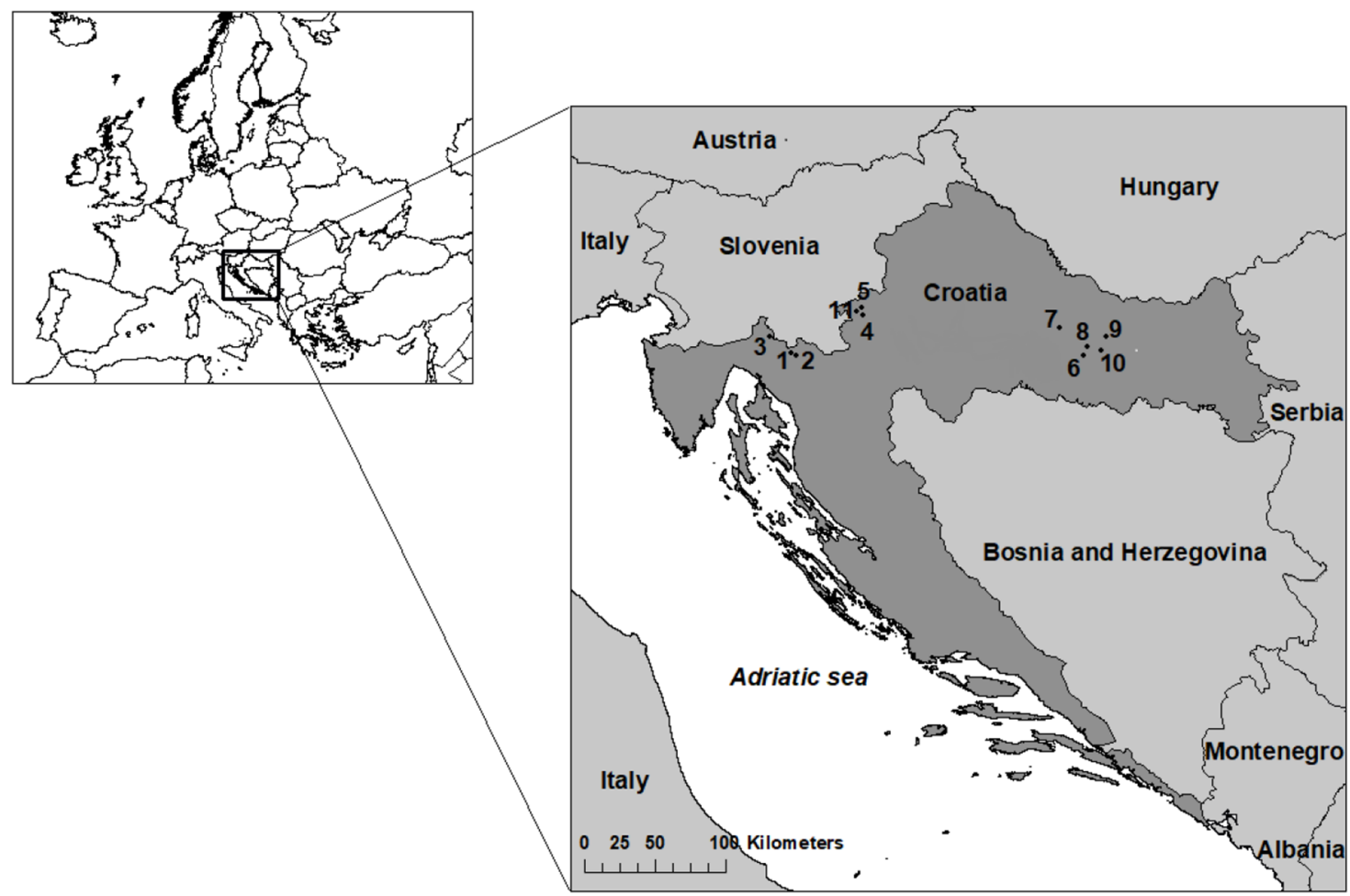

Fig 1. Sampling locations: Gorski Kotar region: 1-Mala Lešnica, 2-Curak, 3-Bresni potok; Mt. Žumberak area: 4-Kupčina, 5-Slapnica, 11-Vrabac fish farm; Mt. Papuk area: 6-Orljava, 7-Toplica, 8-Brzaja, 9-Jankovac, 10-Veličanka.

Table 1. Sampling locations with coordinates and number of sampled trout specimen with affiliation to lineages as determined by molecular methods (sensu Kanjuh et al., 2020) and sex ratio ( $n=$ number of individuals; $\mathrm{TL}_{\min }=$ minimal total length in $\mathrm{cm}$; $\mathrm{TL}_{\max }=\operatorname{maximal}_{\text {total length }}$ in $\mathrm{cm} ; \mathrm{F}=$ female; $\mathrm{M}=$ male).

\begin{tabular}{|c|c|c|c|c|c|c|c|c|c|c|c|c|}
\hline \multirow[t]{3}{*}{ Stream name } & \multicolumn{2}{|c|}{ Coordinates (WGS84) } & \multicolumn{9}{|c|}{ Lineage } & \multirow[t]{3}{*}{ Sex ratio F:M } \\
\hline & \multirow[t]{2}{*}{ Latitude $\left({ }^{\circ} \mathrm{N}\right)$} & \multirow[t]{2}{*}{ Longitude $\left({ }^{\circ} \mathrm{E}\right)$} & \multicolumn{3}{|c|}{ Danubian } & \multicolumn{3}{|c|}{ Atlantic } & \multicolumn{3}{|c|}{ Hybrid } & \\
\hline & & & $n$ & $\mathrm{TL}_{\min }$ & $\mathrm{TL}_{\max }$ & $n$ & $\mathrm{TL}_{\text {min }}$ & $\mathrm{TL}_{\max }$ & $n$ & $\mathrm{TL}_{\min }$ & $\mathrm{TL}_{\max }$ & \\
\hline Mala Lešnica & 45.4381 & 14.8482 & 6 & 11.6 & 30.3 & & & & 4 & 10.0 & 23.9 & 10:0 \\
\hline Curak & 45.4261 & 14.8925 & 5 & 15.5 & 24.9 & 1 & 22.2 & 22.2 & 1 & 27.1 & 27.1 & $7: 0$ \\
\hline Bresni potok & 45.5415 & 14.6490 & & & & 5 & 17.6 & 24.7 & 5 & 13.2 & 22.3 & $10: 0$ \\
\hline Kupčina & 45.6910 & 15.4963 & 1 & 21.5 & 21.5 & & & & 10 & 14.2 & 22.4 & $11: 0$ \\
\hline Slapnica & 45.7401 & 15.4879 & 2 & 12.1 & 21.8 & & & & 8 & 10.0 & 19.9 & $10: 0$ \\
\hline Orljava & 45.4288 & 17.5033 & & & & & & & 4 & 14.4 & 20.5 & $4: 0$ \\
\hline Toplica & 45.6090 & 17.2827 & 1 & 12.0 & 12.0 & & & & 9 & 12.4 & 19.4 & $6: 4$ \\
\hline Brzaja & 45.4894 & 17.5348 & 5 & 15.9 & 20.4 & & & & 4 & 12.8 & 18.6 & $4: 5$ \\
\hline Jankovac & 45.5486 & 17.7065 & 1 & 17.3 & 17.3 & & & & 4 & 13.5 & 17.5 & $3: 2$ \\
\hline Veličanka & 45.4634 & 17.6580 & 1 & 15.5 & 15.5 & 1 & 20.3 & 20.3 & 2 & 15.1 & 23.8 & $1: 3$ \\
\hline Vrabac fish farm & 45.7328 & 15.4216 & & & & 10 & 20.0 & 28.8 & & & & $8: 2$ \\
\hline Total & & & 22 & & & 17 & & & 51 & & & \\
\hline
\end{tabular}

revealed a high degree of hybridization between them. These results enabled the a priori classification of specimens into three groups: Danubian lineage, Atlantic lineage, and their hybrids (Tab. 1). Two specimens were unclassified and excluded from further analysis because of inconclusive results of the genetic analysis, giving a final sample of 90 individuals examined further in this GM analysis.

\subsection{Geometric morphometric protocol and statistics}

\subsubsection{Acquiring landmark data}

All 90 specimens were photographed and shape data based on 19 points (9 landmarks and 10 semi-landmarks) marked on each photograph were obtained using using TPSDig2 software (Rohlf, 2017a). The selection of landmarks and semi- 


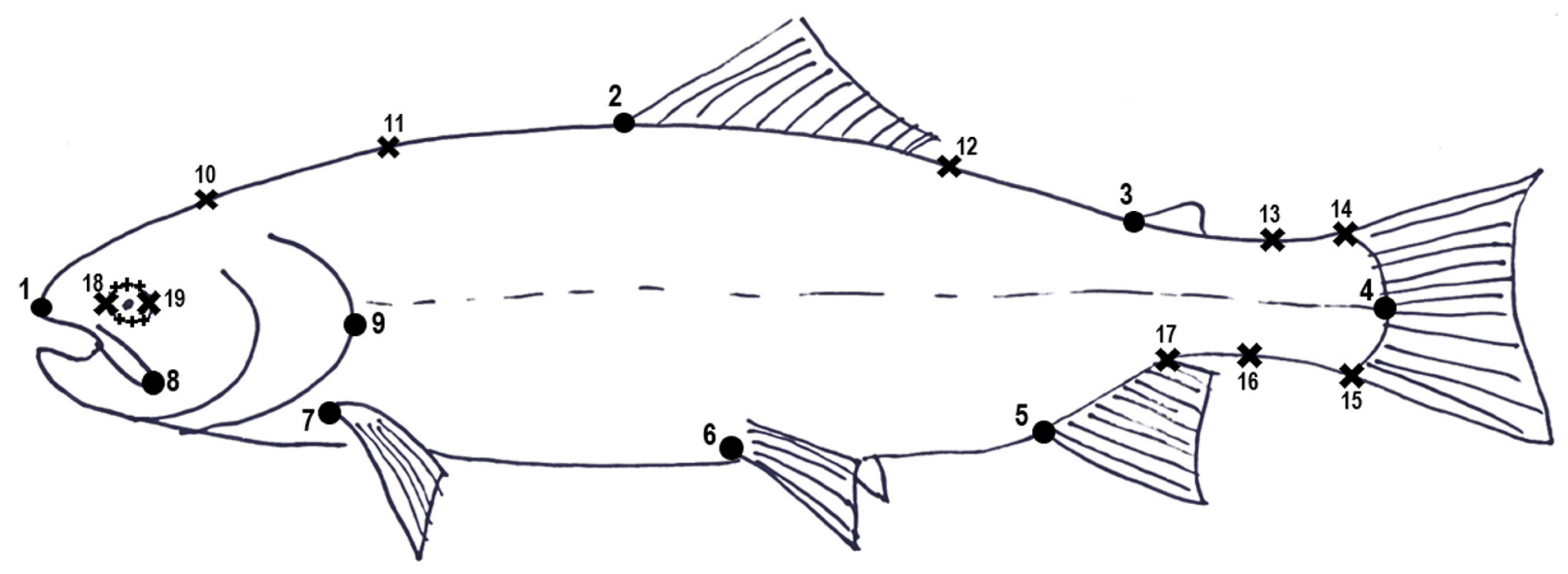

Fig 2. Position of selected points: 9 landmarks (solid circles), 10 semi-landmarks (X marks) and 6 helper points around eyes (pluses) on the left flank of brown trout.

landmarks was based on a combination of points from Monet et al. (2006) and Fruciano et al. (2020) (Fig. 2). An additional 6 helper points were used to digitize trout eyes and were removed before statistical analysis. Scaled and digitized photographs were subjected to Generalized Procrustes Analysis (GPA) with sliding landmarks in TPSrelw software (Rohlf, 2017b). GPA separates the form of an organism into two components, centroid size and shape, and eliminates all other non-shape variation caused by differences in positioning, orientation and scaling. The results of this procedure are Procrustes coordinates that represent shape variables, two for each landmark since the photographs are two-dimensional, and the centroid size that represents the size variable, as the value of the square root of the sum of squared distances of each landmark from their respective centroid (Zelditch et al., 2004).

\subsubsection{Digitization error estimation and dataset preparation}

To evaluate digitization error, a subset of 20 randomly selected individuals was digitized a second time for subsequent analysis with Procrustes ANOVA in MorphoJ software (Klingenberg, 2011) to calculate the values of repeatability (R) for both centroid size and shape defined by the Procrustes coordinates. Repeatability value ranges from 0 to 1 , where measurement error decreases as the value approaches 1 (Fruciano, 2016). Estimated reference values of repeatability according to Koo and $\mathrm{Li}$ (2016) are listed as poor for values less than 0.50 , moderate between 0.50 and 0.75 , good between 0.75 and 0.90 , and excellent when greater than 0.90 .

Arching of fish during presentation can cause irrelevant shape variation. This was remedied by modelling the shape change vector based on 12 intentionally bent individuals from two populations from the original locations, and then projecting the original Procrustes coordinates in the multivariate subspace orthogonal to the modelled vector (Burnaby, 1966; Valentin et al., 2008; Fruciano et al., 2014; Fruciano, 2016) (Figure S1). Between-group principal component analysis (PCA) was applied to Procrustes coordinates with the removed arching effect in two groups (males and females), and then data were projected orthogonally onto this newly generated principal component, thus removing shape change due to sexual dimorphism (Fruciano et al., 2014) (Figure S2). Modelling of vectors and the orthogonal projection of data was performed in the R packages GeometricMorphometricsMix ( $\mathrm{R}$ Core team, 2019) and Morpho (Schlager, 2017). Allometric shape variation of data was removed in MorphoJ software by regressing shape variables onto centroid size, and only residuals of this regression were used as shape data in further analyses (Klingenberg, 2011) (Figure S3).

\subsubsection{Assessment of morphological variation}

Procrustes ANOVA was applied to shape data $(n=90)$ to test shape differences among lineages, since size was not an important factor and the allometric effect was already removed from the data. Possible shape differences between lineages were analysed by canonical variate analysis (CVA). CVA is one of the most frequent types of analysis in morphometrics; it is a multivariate analysis requiring the insertion of a priori descriptors to distinguish among multiple groups of specimens (Klingenberg 2011, Bravi et al., 2013). Discriminant function analysis (DFA) was then applied to the shape data to carry out a leave-one-out cross-validation to assess the reliability of classification. DFA is a method with emphasis on the degree of separation of groups and it is applicable to only two groups at a time, so it was conducted as a pairwise comparison for all three groups (Atlantic lineage, Danubian lineage and hybrids) (Klingenberg, 2011). Permutation tests of Procrustes distances and the T-square statistic were used with Procrustes ANOVA to test the null hypothesis of equal group means. These tests were done in MorphoJ software (Klingenberg, 2011). Crossvalidation scores were used to assess classification accuracy. Wireframe graphs of the mean and displaced landmarks described the significant shape differences. To quantify morphological variations within the entire sample and within specific groups, overall disparity and Procrustes variance of each group and of all specimens were calculated using the morphol.disparity function in the Geomorph package in $\mathrm{R}$ (Adams et al., 2013, 2014). Procrustes variance is the measure of disparity within tested groups, and overall disparity is the quantification of morphospace that all analysed specimens 
Table 2. Procrustes ANOVA on centroid size and shape of the subset of 20 brown trout specimens digitized twice to assess measurement error ( $\mathrm{SS}$ - sum of squares, MS - mean squares, df - degrees of freedom, F - F ratio).

\begin{tabular}{llllll}
\hline Effect & SS & MS & df & $F$ & $p$ (parametric) \\
\hline Centroid size & & & & 19 & 1378.1500 \\
Individual & 1336.3827 & 70.3359 & 20 & & $<0.0001$ \\
Digitization error & 1.0207 & 0.0510 & & 14.2800 & $<0.0001$ \\
Shape & & & 646 & 680 & \\
Individual & 0.0438 & $6.7760 \mathrm{E}-5$ & $4.7435 \mathrm{E}-6$ & & \\
Digitization error & 0.0032 & & & \\
\hline
\end{tabular}

Table 3. Procrustes ANOVA on shape of trout $(n=90)$ ( $\mathrm{SS}-$ sum of squares, MS - mean squares, df - degrees of freedom, $F-F$ ratio).

\begin{tabular}{llllll}
\hline Effect & SS & MS & df & $F$ & $p$ (parametric) \\
\hline Shape & & & & & \\
Lineage & 0.0033 & $4.8870 \mathrm{E}-5$ & 68 & 3.0000 & $<0.0001$ \\
Individual & 0.0482 & $1.6297 \mathrm{E}-6$ & 2958 & & \\
\hline
\end{tabular}

Table 4. Results of CVA and DFA statistic tests for compared groups of trout.

\begin{tabular}{|c|c|c|c|c|c|c|}
\hline \multirow[t]{2}{*}{ Compared groups } & \multicolumn{2}{|c|}{ Canonical Variate Analysis (CVA) } & \multicolumn{4}{|c|}{ Discriminant Function Analysis (DFA) } \\
\hline & $\begin{array}{l}\text { Procrustes } \\
\text { distance }\end{array}$ & $\begin{array}{l}\text { Permutation } \\
\text { test } p \text {-value }\end{array}$ & $\begin{array}{l}\text { Procrustes } \\
\text { distance }\end{array}$ & $\begin{array}{l}\text { Permutation } \\
\text { test } p \text {-value }\end{array}$ & $T$-square & $\begin{array}{l}T \text {-square } p \text {-value } \\
\text { (permutations) }\end{array}$ \\
\hline Atlantic - Danubian & 0.0144 & 0.0015 & 0.0144 & 0.0020 & 965.1081 & 0.0290 \\
\hline Atlantic - hybrids & 0.0121 & 0.0007 & 0.0121 & $<0.0001$ & 251.5185 & $<0.0001$ \\
\hline Danubian - hybrids & 0.0060 & 0.3597 & 0.0060 & 0.3500 & 50.6808 & 0.6970 \\
\hline
\end{tabular}

occupy (Zelditch et al., 2004). To test for statistical differences in disparity between groups, absolute differences in Procrustes variances between groups were used as test statistics in a permutation procedure (1000 permutations), where the Procrustes variances residuals are randomised among groups (Attard et al., 2018). Variation of shape within every group was additionally explored and visualised by PCA. The significance level for all tests was set at 5\%.

\section{Results}

The results of digitization error assessment with Procrustes ANOVA $(n=20)$ are presented in Table 2. The resulting sum of squares showed that the mean squares of individual variation for both centroid size and shape exceeded the mean squares of error in digitization; moreover, the repeatability values were excellent for centroid size $(R=0.9986)$, and good to excellent for shape $(R=0.8692)$, enabling further analysis.

Procrustes ANOVA of shape data $(n=90)$ showed significant differences $(p<0.05)$ of shape between lineages (Tab. 3). Both CVA and DFA resulted in the same values of Procrustes distances and similar permutation test $p$-values (Tab. 4), indicating a significant difference between the shape of Atlantic lineage trout with both the Danubian lineage trout and hybrids, while shape differences between the Danubian lineage and hybrids were not significant. Results of the CVA showed a clear separation of the Atlantic lineage trout from the Danubian lineage and hybrid trout along the CV1 axis, with Danubian and hybrid trout positioned towards the negative end and Atlantic trout toward the positive end (Fig. 3). CV2 separated trout from the Danubian lineage and hybrids to some extent, with Danube trout leaning towards the positive and hybrids towards the negative end of CV2. The first two canonical variates (CV1 83.4500\% and CV2 16.5500\%) explained $100 \%$ of the total variation in shape. A crossvalidation test within DFA also showed that shape differences were least pronounced between Danubian lineage trout and hybrid trout (Tab. 5), as expected.

Shape change along the CV1 axis was mostly determined by body depth, head length and eye size, separating the Atlantic lineage trout from the Danubian lineage trout and hybrids that clustered closer together (Fig. 3). The change in body depth along CV1 (between the negative and positive extremes) was shown by the position of landmarks $11,2,3,17$, 6 and 7; change in head length by the distances of landmarks 1 and 9, and change in eye size by landmarks 18 and 19 (Fig. 3). Individuals of the Danubian lineage and hybrids (shape associated with the negative extreme) had a more streamlined body and elongated head with larger eyes than Atlantic lineage trout (shape associated with the positive extreme). There were some subtle differences in body shape along CV2, with the 

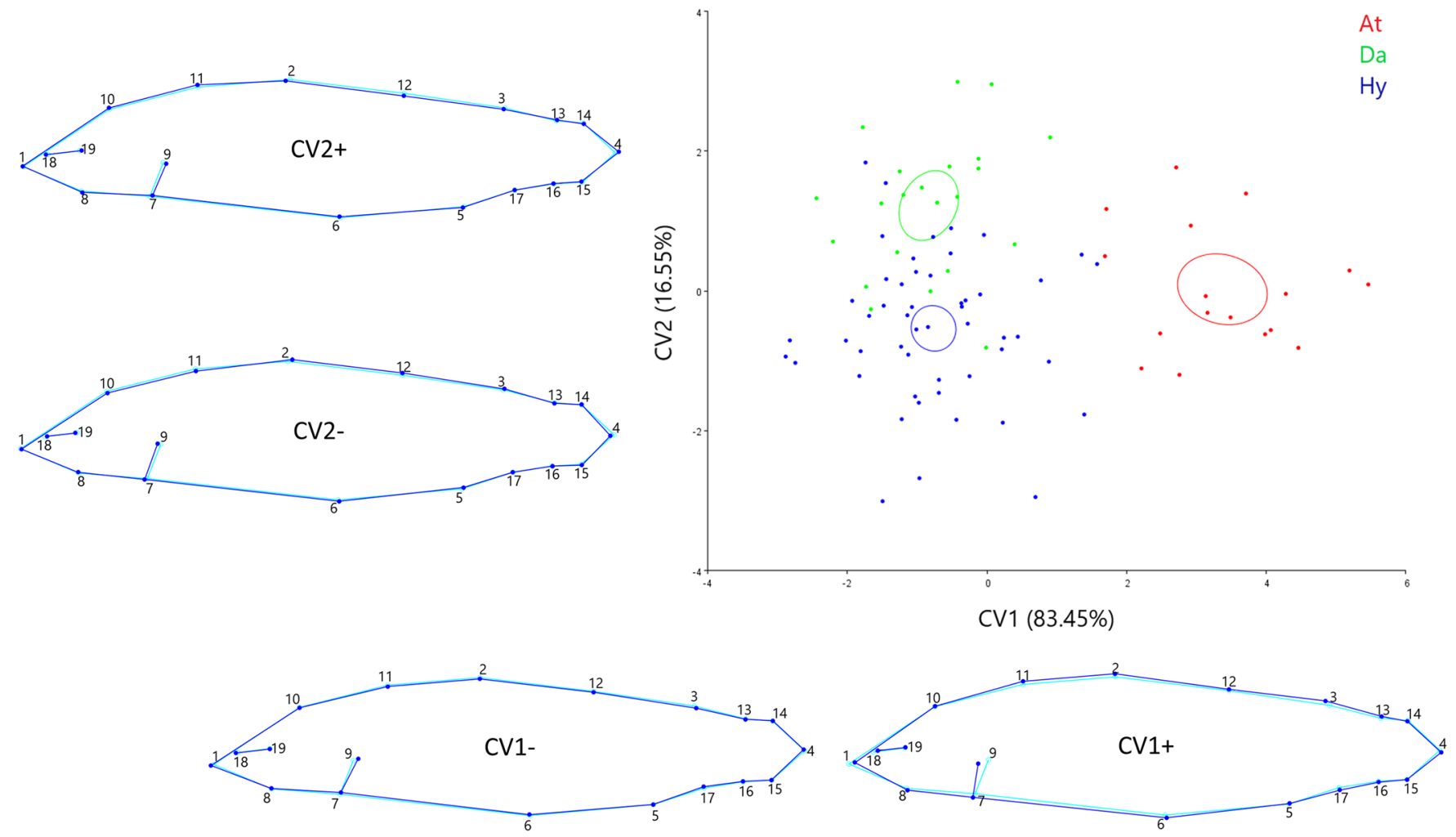

Fig 3. Scatterplot of the first two canonical variate axes of CVA depicting trout shape variation, including mean ellipses. Wireframe graphs with 19 marked landmarks represent shape change along the first and second CV axes, from negative to positive extremes. Light blue outlines represent the average shape and dark blue outlines represent extreme shape changes. At - Atlantic lineage, Da - Danubian lineage, Hy - hybrid.

Table 5. Results of the cross-validation test in DFA for the compared groups of trout. Numbers in brackets represent the correctly assigned individuals in relation to the total number of compared individuals.

\begin{tabular}{llll}
\hline & Atlantic lineage & Danubian lineage & Hybrids \\
\hline Atlantic lineage & & $53 \%(9 / 17)$ & $76 \%(13 / 17)$ \\
Danubian lineage & $68 \%(15 / 22)$ & & $45 \%(10 / 22)$ \\
Hybrids & $84 \%(43 / 51)$ & $53 \%(27 / 51)$ & \\
\hline
\end{tabular}

anterior part of the body moving upwards and the posterior part moving downwards in comparing negative to positive extremes. There were certain changes in head length along $\mathrm{CV} 2$, as Danube lineage trout were associated with having longer heads (positive extreme) than hybrid trout (negative extreme), though these differences were not statistically significant.

The Procrustes variance for overall disparity of the shape of tested lineages was 0.0005 . The group-specific Procrustes variance was $6.9000 \mathrm{E}-4$ for Atlantic lineage, $5.4000 \mathrm{E}-4$ for Danubian lineage and $4.9000 \mathrm{E}-4$ for hybrids. The only significant difference in Procrustes variance was determined between the Atlantic lineage and hybrids (Tab. 6). Since they had the largest variance, DFA was conducted on Atlantic individuals to test if the larger variance was the result of differences between farmed and wild samples (Vrabac farm samples vs. two stream locations), though no significant
Table 6. Pairwise comparison of Procrustes variance between groups. Values under diagonale are the observed pairwise absolute differences (distances) among group Procrustes variances. Values above diagonale are $p$-values associated with pairwise differences (1000 permutations).

\begin{tabular}{llll}
\hline & Atlantic & Danubian & Hybrids \\
\hline Atlantic & - & 0.0750 & 0.0080 \\
Danubian & $1.4600 \mathrm{E}-04$ & - & 0.3890 \\
Hybrids & $1.9900 \mathrm{E}-04$ & $5.2400 \mathrm{E}-05$ & - \\
\hline
\end{tabular}

difference in shape was determined $(p=0.085)$. The PCA along the first two principal components showed that head length and body height variation were present in all three groups, though body height was less variable in the Atlantic lineage when compared to the two other groups (Figures S5-S7).

\section{Discussion}

Digitization error is usually low when performed by the same operator (Fruciano, 2016). Procrustes ANOVA used for error estimation showed that the mean square for individual variation of centroid size and shape was higher than the measurement error, and repeatability values were estimated to be high enough to continue with further analysis (Benítez 
et al., 2014; Fruciano, 2016; Koo and Li, 2016; Lovrenčić et al., 2020). Size-related allometric shape variation was removed from the data because of the different size ranges between group samples and the lack of small individuals in the Atlantic lineage sample (Tab. 1), which could interfere with allometry interpretations (Bravi et al., 2013). This process of allometry effect removal, when size-related allometric component is not of primary interest, has been performed in studies on shape differences between different fish populations (Fruciano et al., 2011, 2014; Stelkens et al., 2012). Procrustes ANOVA can be used to test the significance of shape differences between populations of the same species (Benítez et al., 2014) and the results of this analysis showed that there were significant differences between the lineages of brown trout examined here. CVA and DFA confirmed the significant distinctness of shape of the Atlantic lineage trout from the Danubian lineage trout and hybrids, with no distinctness found between the Danubian lineage and hybrids. A high discriminatory power between pure trout lineages was shown by Simonović et al. (2007) using discriminant analysis on distances between landmarks. They reported that trout stock of the Atlantic lineage from the Trešnjica fish farm were clearly distinct $(100 \%$ correctly classified individuals $)$ from the wild, genetically pure, native trout of the Danubian lineage in the streams of western Serbia void of stocking. Differentiation was possible by characters on the head (e.g., total head length, preocular length, lower jaw length, ventral head length), medial fins (dorsal fin base and anal fin base lengths) and caudal peduncle (anterior height). Monet et al. (2006) investigated morphological variation in brown trout populations comprised of the native Mediterranean lineage, introduced Atlantic lineage, and their hybrids, with significant shape differences determined between all groups using the GM approach. They concluded that most morphological variation pertained to body curvature and sexual dimorphism, while morphological variation caused by genotype was in third place. In this study, shape change due to arching and sexual dimorphism was excluded from the data, together with allometry, as this was not the focus of this study (see Fruciano et al., 2014). Further, Monet et al. (2006) stated that morphological variation caused by genotype was mainly attributable to differences between Mediterranean and Atlantic lineages, making the identification of hybrid trout difficult as they were generally confused with Mediterranean specimens. Similar results for Mediterranean and Atlantic trout lineages and their hybrids were obtained in Italy by Lorenzoni et al. (2019). They used a box truss network and spatial arrangement of dots, and determined a significant difference between all three groups. Separation was more obvious between pure Mediterranean and Atlantic lineages, while hybrid individuals tended to overlap with the Mediterranean lineage, making hybrid identification difficult. Other morphometry studies have shown that either body height (or body elongation) (Monet et al., 2006; Fruciano et al., 2014; Ninua et al., 2018), head length (Simonović et al., 2007; Delling et al., 2020), or both (Pakkasmaa, 2001; Hermida et al., 2009) are distinctive features among different lineages or forms within the brown trout complex. The present study has demonstrated that body height, head length, and eye size were the main differentiating characteristics between the Danubian trout lineage and introduced Atlantic specimens.
Salmonids are known for their high phenotypic plasticity (Fleming et al., 1994; Stelkens et al., 2012; Fruciano et al., 2014; Piria et al., 2020). Individual phenotype is not only determined by its genotype but can also be shaped by habitat within a single generation of culturing, as observed in Salmo salar, where individuals cultured on fish farms tended to have smaller heads and fins and a narrower caudal peduncle (Fleming et al., 1994). It is debatable if the differences detected in body and head shape of trout in this study were the result of genetic differentiation alone, or also of habitat (wild vs. farmed). Stocking of streams in Croatia is primarily based on imported trout of Atlantic lineage grown on salmonid fish farms (Piria et al., 2020), which could be why there were no significant differences in shape between the Atlantic samples taken from farms and streams. Therefore, the pure Atlantic trout sampled from natural streams in this study are actually specimens originating from fish farms, and their shape could be the result of adaptation to farming conditions, as discussed in Monet et al. (2006). The Procrustes variance showed that Atlantic trout had the largest shape variability among the tested groups, attributable mostly to head length variation, as variability in body height was lower in the Atlantic lineage than in the other two groups. Variation in overall body shape is one of the best-known morphological responses in salmonids to flow regimes, and is heritable (Stelkens et al., 2012). This lower variation in body height could be additional proof of the influence of fish farm origin on the shape of all Atlantic specimens in this study. The hybrids analysed here share genes with Danubian trout (Kanjuh et al., 2020), and moreover they hatched and evolved in the same habitats as pure Danubian trout. As such, adaptations to the same habitats could be similar due to their high phenotypic plasticity, explaining why the shape of hybrids did not differ significantly from the shape of pure Danubian populations. In addition, Jansson et al. (1991), Matthews et al. (2000) and Kalayci et al. (2018) noted that morphological distinctions of hybrid salmonids from parental species are generally unreliable. However, both Monet et al. (2006) and Lorenzoni et al. (2019) showed that it is possible to find significant shape distinction between hybrid trout and both parental populations, though they examined parental populations from the Mediterranean and Atlantic lineage, and still hybrids were more similar to the native Mediterranean parental lineage populations.

The main limitation of this research was the small sample of wild collected specimens, which may have influenced the significance of the obtained results. The Veličanka, Jankovac and Orljava streams are small and shallow, with scarce trout populations, and it was not possible or justifiable to take more individuals for laboratory studies. Since the number of individuals of pure Atlantic trout, especially those sampled from natural streams in this study was low (only 7 specimens), future research should include a larger sample size and investigate shape changes between trout of the pure Atlantic lineage from fish farms and those sampled from natural streams, but not limited only to the Danube Basin. Such an approach could enable obtaining Atlantic lineage trout hatched in the wild. There was an overall dominance of female specimens in the sample, with no males captured in six streams. It is not clear how this imbalance could influence the final results, though variation associated with sexual dimorphism was removed. Furthermore, analysis was performed on 
fish thawed in the laboratory after being frozen, which could further influence fish body shape (Fruciano et al., 2020), though all specimens in this study were collected, stored and handled in the same manner. In future study, the inclusion of landmarks to examine the lower jaw and head depth could give additional insight into the ecologies of the lineages, as head morphology can reflect trophic variation (Wainwright et al., 1991; Piggott et al., 2018), and these additional landmarks could better explain the largest Procrustes variation within the Atlantic lineage.

Kanjuh et al. (2020) found that none of the sampled streams included in this study contained completely pure Danube trout lineage populations, with at least one hybrid or Atlantic lineage individual with Atlantic trout lineage genes detected at each site. The present study indicated a difference in shape between trout belonging to the Danubian and Atlantic lineages. This distinction could be helpful in the recognition, management and conservation of the pure Danube lineage, in order to preserve its evolutionary heritage.

\section{Supplementary Material}

Figure S1. Shape change along PC1 of modelled arching shape variation that was removed, since it is biologically irrelevant.

Figure S2. Removed shape change depicting sexual dimorphism and obtained by between-group PCA.

Figure S3. Removed shape change associated with centroid size (allometric shape variation).

Figure S4. Shape change between the three trout lineages, determined by DFA.

Figure S5. Scatterplot of the first two principal components of PCA depicting trout shape variation within Atlantic lineage. Wireframe graphs with marked landmarks represent shape change along the first and second principal components, from negative to positive end.

Figure S6. Scatterplot of the first two principal components of PCA depicting trout shape variation within Danubian lineage. Wireframe graphs with marked landmarks represent shape change along the first and second principal components, from negative to positive end.

Figure S7. Scatterplot of the first two principal components of PCA depicting trout shape variation within hybrid group. Wireframe graphs with 19 marked landmarks represent shape change along the first and second principal components, from negative to positive end.

Table S1. Eigeinvalues in the PCA for shape variation of Atlantic lineage trout.

Table S2. Principal component coefficients of corresponding Procrustes coordinates for first two PCs in the PCA for shape variation of Atlantic lineage trout.

Table S3. Eigeinvalues in the PCA for shape variation of Danubian lineage trout.

Table S4. Principal component coefficients of corresponding Procrustes coordinates for first two PCs in the PCA for shape variation of Danubian lineage trout.

Table S5. Eigeinvalues in the PCA for shape variation of hybrid trout.
Table S6. Principal component coefficients of corresponding Procrustes coordinates for first two PCs in the PCA for shape variation of hybrid trout.

The Supplementary Material is available at https://www.kmaejournal.org/10.1051/kmae/2021021/olm.

Acknowledgements. The research was supported by Croatian Science Foundation grant IP-2016-06-2563 "Climate change and invasive species - assessing effects onto biodiversity of native freshwater crayfish and salmonids and their conservation". Special thanks to Tomo Vrabac, owner of the Vrabac fish farm, for donating farmed trout individuals for this research. We thank Petra Kristan for her assistance in preparing the trout photographs used for GM in this study. We thank Carmelo Fruciano for his guidance on the arching effect removal method, and Linda Zanella for proofreading the manuscript and providing constructive comments. We would also like to thank the anonymous reviewers for their constructive comments that greatly improved the manuscript.

\section{References}

Adams DC, Otarola-Castillo E. 2013. Geomorph: an R package for the collection and analysis of geometric morphometric shape data. Methods Ecol Evol 4: 393-399.

Adams DC, Otarola-Castillo E, Sherratt E. 2014. Geomorph: Software for geometric morphometric analyses. R package version 2.0. http://cran.r-project.org/web/packages/geomorph/index.html.

Allendorf FW, Leary RF, Spruell P, Wenburg JK. 2001. The problems with hybrids: setting conservation guidelines. Trends Ecol Evol 16: 613-622.

Attard MRG, Sherratt E, Mcdonald P, Young I, Vidal-García M, Wroe S. 2018. A new, three-dimensional geometric morphometric approach to assess egg shape. PeerJ 6: e 5052.

Bernatchez L. 2001. The evolutionary history of brown trout (Salmo trutta L.) inferred from phylogeographic, nested clade, and mismatch analyses of mitochondrial DNA variation. Evolution 55: 351-379.

Berrebi P. 2015. Three brown trout Salmo trutta lineages in Corsica described through allozyme variation. J Fish Biol 86: 60-73.

Burnaby T. 1966. Growth-invariant discriminant functions and generalized distances. Biometrics 22: 96-110.

Benítez HA, Püschel T, Lemić D, Čačija M, Kozina A, Bažok R. 2014. Ecomorphological variation of the wireworm cephalic capsule: Studying the interaction of environment and geometric shape. PLOS ONE 9: e102059.

Bravi R, Ruffini M, Scalici M. 2013. Morphological variation in riverine cyprinids: a geometric morphometric contribution. Ital $J$ Zool 80: 536-546.

Chaiphongpachara T. 2018. Comparison of landmark- and outlinebased geometric morphometrics for discriminating mosquito vectors in Ratchaburi Province, Thailand. BioMed Res Int 2018: $1-10$.

Delling B, Sabatini A, Muracciole S, Tougard C, Berrebi P. 2020. Morphologic and genetic characterisation of Corsican and Sardinian trout with comments on Salmo taxonomy. Knowl Manag Aquat Ecosyst 421: 21.

Fleming IA, Jonsson B, Gross MR. 1994. Phenotypic divergence of sea-ranched, farmed, and wild salmon. Can J Fish Aquat Sci 51: $2808-2824$. 
Fruciano C, Tigano C, Ferrito V. 2011. Geographical and morphological variation within and between colour phases in Coris julis (L. 1758), a protogynous marine fish. Biol J Linn Soc 104: 148-162.

Fruciano C, Pappalardo AM, Tigano C, Ferrito V. 2014. Phylogeographical relationships of Sicilian brown trout and the effects of genetic introgression on morphospace occupation. Biol J Linn Soc 112: 387-398.

Fruciano C. 2016. Measurement error in geometric morphometrics. Dev Genes Evol 226: 139-158.

Fruciano C, Schmidt D, Ramírez Sanchez MM, Morek W, Valle ZA, Talijančić I, Pecoraro C, Legionnet AS. 2020. Tissue preservation can affect geometric morphometric analyses: a case study using fish body shape. Zool J Linn Soc 188: 148-162.

Georgijev BV. 2003. On the origin of the Balkan Peninsula Salmonids. Croat J Fish 61: 147-174.

Hermida M, San Miguel E, Bouza C, Castro J, Martínez P. 2009. Morphological variation in a secondary contact between divergent lineages of brown trout (Salmo trutta) from the Iberian Peninsula Genet Mol Biol 32: 42-50.

Ivić L, Buj I, Raguž L, Marčić Z, Ćaleta M, Zanella D, Mustafić P, Horvatić S. 2021. Diversity and structure of trout populations (Salmo sp., Salmonidae, Actinopteri) in the Žumberak-Samoborsko Gorje Nature Park in Croatia. Fundam Appl Limnol 194: 215-225.

Jansson H, Holmgren I, Wedin K, Andersson T. 1991. High-frequency of natural hybrids between Atlantic Salmon, Salmo salar L., and brown trout, Salmo trutta L., in a Swedish River. J Fish Biol 39: 343-348.

Kalayci G, Ozturk RC, Capkin E, Altinok I. 2018. Genetic and molecular evidence that brown trout Salmo trutta belonging to the Danubian lineage are a single biological species. J Fish Biol 93: 792-804.

Kanjuh T, Marić A, Piria M, Špelić I, Maguire I, Simonović P. 2020. Diversity of brown trout, Salmo trutta (Actinopterygii: Salmoniformes: Salmonidae), in the Danube River basin of Croatia revealed by mitochondrial DNA. Acta Ichthyol Piscat 50: 291-300.

Khaefi R, Esmaeili HR, Chermahini MA. 2018. Natural hybridization of Luciobarbus barbulus x Luciobarbus kersin and Luciobarbus barbulus x Luciobarbus xanthopterus in the Persian Gulf Basin. TrJFAS 18: 1399-1407.

Klingenberg CP. 2011. MorphoJ: an integrated software package for geometric morphometrics. Mol Ecol Resour 11: 353-357.

Koo TK, Li MY. 2016. A guideline of selecting and reporting intraclass correlation coefficients for reliability research. $J$ Chiropractic Med 15: 155-163.

Leitwein M, Guinand B, Pouzadoux J, Desmarais E, Berrebi P, Gagnaire PA. 2017. A dense brown trout (Salmo trutta) linkage map reveals recent chromosomal rearrangements in the Salmo genus and the impact of selection on linked neutral diversity. G3-Genes Genom Genet 7: 1365-1376.

Liasko R, Anastasiadou C, Ntakis A, Gkenas C, Leonardos ID. 2012. Morphological differentiation among native trout populations in North-Western Greece. J Biol Res-Thessalon 17: 33-43.

Lorenzoni M, Carosi A, Giovannotti M, La Porta G, Splendiani A, Caputo Barucchi V. 2019. Morphological survey as powerful detection tool of pure and local phenotypes in Salmo trutta complex. Knowl Manag Aquat Ecosyst 420: 48.

Lovrenčić L, Pavić V, Majnarić S, Abramović L, Jelić M, Maguire I. 2020. Morphological diversity of the stone crayfish - traditional and geometric morphometric approach. Knowl Manag Aquat Ecosyst 421: 1 .
Matthews MA, Poole WR, Thompson CE, Mckillen J, Ferguson A, Hindar K, Wheelan KF. 2000. Incidence of hybridization between Atlantic salmon, Salmo salar L. and brown trout, Salmo trutta L., in Ireland. Fish Manag Ecol 7: 337-347.

Monet G, Uyanik A, Champigneulle A. 2006. Geometric morphometrics reveals sexual and genotypic dimorphisms in the brown trout. Aquat Living Resour 19: 47-57.

Ninua L, Tarkhnishvili D, Gvazava E. 2018. Phylogeography and taxonomic status of trout and salmon from the Ponto-Caspian drainages, with inferences on European Brown Trout evolution and taxonomy. Evol Ecol 8: 2645-2658.

Pakkasmaa S. 2001. Morphological differentiation among local trout (Salmo trutta) populations. Biol J Linn Soc 72: 231-239.

Piggott CVH, Verspoor E, Greer R, Hooker O, Newton J, Adams CE. 2018. Phenotypic and resource use partitioning amongst sympatric, lacustrine brown trout, Salmo trutta. Biol J Linn Soc 124: 200-212.

Piria M, Špelić I, Rezić A, Šprem N. 2020. Morphological traits and condition of brown trout Salmo trutta from Žumberak and Samobor mountain streams. J Cent Eur Agric 21: 231-245.

Pofuk M, Zanella D, Piria M. 2017. An overview of the translocated native and non-native fish species in Croatia: pathways, impacts and management. Manag Biol Invasions 8: 425-435.

R Core team. 2019. R: A language and environment for statistical computing. Vienna, Austria: R Foundation for Statistical Computing.

Rohlf FJ. 2017a. TPSDig2, version 2.30. Stony Brook NY: Department of Ecology and Evolution, State University of New York. Available at: http://www.sbmorphometrics.org/ (accessed 22.12.2020)

Rohlf FJ. 2017b. TPSrelw, version 1.69. Stony Brook NY: Department of Ecology and Evolution, State University of New York. Available at: https://tpsrelw.software.informer.com/1.5/ (accessed 20.04.2021)

Saint-Pé K, Leitwein M, Tissot L, Poulet N, Guinand B, Berrebi P, Marselli G, Lascaux JM, Gagnaire PA, Blanchet S. 2019. Development of a large SNPs resource and a low-density SNP array for brown trout (Salmo trutta) population genetics. BMC Genom 20: 582.

Sanz N. 2018. Phylogeographic history of brown trout: a review. In: Lobon-Cervia J, Sanz N (eds.). Brown trout: biology, ecology and management. Hoboken, New Jersey, USA: John Wiley and Sons Ltd., pp. 525-543.

Schlager S. 2017. Morpho and Rvcg - Shape Analysis in R. In: Zheng G, Li S, Szekely G (eds.). Statistical Shape and Deformation Analysis Methods, Implementation and Applications. Amsterdam: Elsevier, pp. 217-256.

Scribner KT, Page KS, Bartron ML. 2001. Hybridization in freshwater fishes: a review of case studies and cytonuclear methods of biological inference. Rev Fish Biol Fisher 10: 293-323.

Simonović P, Marić S, Nikolić V. 2007. Trout Salmo spp. complex in Serbia and adjacent regions of the western Balkans: reconstruction of evolutionary history from external morphology. J Fish Biol 70: 359-380.

Snoj A, Marić S, Bajec SS, Berrebi P, Janjani S, Schöffmann J. 2011. Phylogeographic structure and demographic patterns of brown trout in North-West Africa. Mol Phylogenet Evol 61: 203-211.

Stelkens RB, Jaffuel G, Escher M, Wedekind C. 2012. Genetic and phenotypic population divergence on a microgeographic scale in brown trout. Mol Ecol 21: 2896-2915.

Škraba Jurlina D, Marić A, Mrdak D, Kanjuh T, Špelić I, Nikolić V, Piria M, Simonović P. 2020. Alternative life-history in native trout (Salmo spp.) suppresses the invasive effect of alien trout strains introduced into streams in the Western part of the Balkans. Front Ecol Evol 8: 188. 
Uemura Y, Yoshimi S, Hata H. 2018. Hybridization between two bitterling fish species in their sympatric range and a river where one species is native and the other is introduced. PLOS ONE 13: $\mathrm{e} 0203423$.

Vasil'eva ED, Vasil'ev VP. 2019. Natural hybridization in spined loaches of the genera Cobitis and Sabanejewia (Cobitidae). J Ichthyol 59: 776-785.

Valentin AE, Penin X, Chanut JP, Sévigny JM, Rohlf FJ. 2008. Arching effect on fish body shape in geometric morphometric studies. J Fish Biol 73: 623-638.
Wainwright PC, Osenberg CW, Mittelbach GG. 1991. Trophic polymorphism in the pumpkinseed sunfish (Lepomis gibbosus Linnaeus): effects of environment on ontogeny. Funct Ecol 5: 40-55.

Webster M, Sheets HD. 2010. A practical introduction to landmarkbased geometric morphometrics. In: Alroy J, Hunt G. (eds.) Quantitative Methods in Paleobiology. UK: The Paleontological Society Papers, Cambridge Core, pp. 163-188.

Zelditch ML, Swiderski DL, Sheets HD. 2004. Geometric Morphometrics for Biologists: a primer. Amsterdam: Elsevier, p. 478.

Cite this article as: Špelić I, Rezić A, Kanjuh T, Marić A, Maguire I, Simonović P, Radočaj T, Piria M. 2021. Application of the geometric morphometrics approach in the discrimination of morphological traits between brown trout lineages in the Danube Basin of Croatia. Knowl. Manag. Aquat. Ecosyst., 422, 22. 